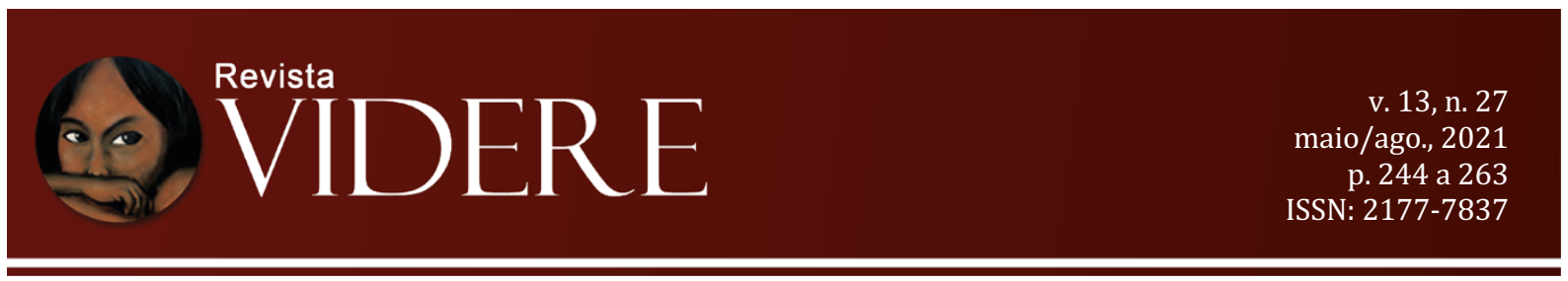

\title{
CIVILIZAR LA BARBARIE: PODER Y HEGEMONÍA DEL DISCURSO JURÍDICO DESDE EL MARTÍN FIERRO. ESTUDIOS DE DERECHO Y LITERATURA EN ARGENTINA
}

\author{
CIVILIZE THE BARBARISM: POWER AND HEGEMOMONY OF THE LEGAL \\ DISCOURSE IN MARTÍN FIERRO. LAW AND LITERATURE STUDIES IN \\ ARGENTINA
}

\begin{abstract}
CIVILIZAR A BARBÁRIE: PODER E HEGEMONIA DO DISCURSO JURÍDICO EM MARTÍN FIERRO. ESTUDOS DE DIREITO E LITERATURA NA ARGENTINA
\end{abstract}

\author{
Gonzalo Ana Dobratinich \\ Magister en Filosofía del Derecho (UBA) \\ Doctorando en Derecho (UBA - UMA, España) \\ CONICET - Facultad de Derecho (UBA) \\ gonzaloanadobra@gmail.com \\ OrcidID: https://orcid.org/0000-0002-6548-8700
}

Resumen: El presente artículo se propone indagar en torno a los mecanismos y dispositivos que permiten la auto-legitimación y centralidad del discurso jurídico. Las herramientas metodológicas que aportan los estudios iusfilosóficos de "derecho y literatura", permiten visibilizar otras perspectivas narrativas que emergen por fuera del relato hegemónico al mismo tiempo que plantean su resignificación. En este orden de ideas, el poema narrativo Martín Fierro ofrece categorías e instrumentos teóricos capaces de analizar la construcción del discurso jurídico. Como parte del proceso de organización política del siglo XIX, las categorías de sujeto, ley, violencia, barbarie o Estado no solo serán desarrolladas y constituidas desde el derecho argentino sino también expuestas y desarticuladas por el texto de José Hernández.

Palabras clave: Filosofía del derecho. derecho y literatura. análisis crítico del discurso. poder. hegemonía.

Abstract: This article aims to investigate the mechanisms and devices that allow the selflegitimation and centrality of legal discourse. The methodological tools provided by the iusphilosophical studies of "law and literature" allow the visibility of other narrative perspectives that emerge outside the hegemonic narrative at the same time that they propose its resignification. In this order of ideas, the narrative poem Martín Fierro offers categories and theoretical instruments capable of analyzing the construction of legal discourse. As part of the process of political organization in the nineteenth century, the categories of subject, law, 
violence, barbarism or State will not only be developed and constituted from Argentine law but also exposed and disjointed by the text of José Hernández.

Keywords: Philosophy of law. law and literature. critical discourse analysis. power. hegemony.

Resumo: Este artigo tem como objetivo investigar os mecanismos e dispositivos que permitem a autolegitimação e a centralidade do discurso jurídico. As ferramentas metodológicas fornecidas pelos estudos iusfilosóficos do "direito e da literatura" permitem tornar visíveis outras perspectivas narrativas que emergem fora da história hegemônica ao mesmo tempo que propõem sua ressignificação. Nessa ordem de ideias, o poema narrativo Martín Fierro oferece categorias e instrumentos teóricos capazes de analisar a construção do discurso jurídico. Como parte do processo de organização política do século XIX, as categorias de sujeito, lei, violência, barbárie ou Estado não só serão desenvolvidas e constituídas a partir do direito argentino, mas também expostas e desarticuladas pelo texto de José Hernández.

Palavras-chave: Filosofia do direito. direito e literatura. análise crítica do discurso. poder. hegemonia.

\section{Introducción}

La literatura argentina propone fructíferos aportes conceptuales para analizar las diferentes áreas del derecho. Las estructuras literarias se inmiscuyen en temáticas jurídicas, lo que nos autoriza una lectura en clave “iusliteraria” (CALVO GONZÁLEZ, 2016b, p. 12; CALVO GONZÁLEZ, 2018, p. 3-44; CALVO GONZÁLEZ, 2019, p. 105-137). Para ello será necesario articular posiciones epistemológicas que visibilicen las discontinuidades, rupturas y articulaciones discursivas que se producen entre ambas disciplinas (FOUCAULT, 2008, p. 1819).

En uno de sus versos, el profuso colosal texto de Hernández indica: "Para él son los calabozo, / para él las duras prisiones; /en su boca no hay razones / aunque la razón le sobre; / que son campanas de palo / las razones de los pobres" (HERNÁNDEZ, 2010, p. 76). El poema narrativo, pone en suspenso la referencialidad. Sin forzar el texto, esa insubordinación semántica, que excede a su autor, hacen viable una lectura más amplia en términos jurídicos. La literatura se adelanta, a su manera expone y propone el análisis de ciertos tópicos con anterioridad a otros tipos de saberes.

No es el gaucho, es la constitución de las categorías de individuo, persona y sujeto. No es su analfabetismo legal sino la plataforma en que el derecho de despliega, sus luces y su necesaria diferencia, su opacidad (CÁRCOVA, 2007, p. 16-19). No es una forma de expresión de la cultura, es la discusión sobre la construcción del conocimiento. No es la discriminación 
de clase es el imaginario social, la política criminal, la violencia que habilita el discurso oficial (MARÍ, 1986, p. 95-98).

\section{Organización, narrativas y Estado}

Un año antes de que la Constitución Nacional de la República Argentina sentara las bases jurídicas del Estado, se produce el inicio de un nuevo período histórico, conocido como “Organización Nacional”. En esta etapa, que irá desde 1852 a 1880, se considera superada la problemática independentista, por lo que el ejercicio crítico se orientará al análisis de la sociedad argentina. Ello no implicará un corte abrupto con el período anterior, sino que por el contrario habrá encadenamiento de las perspectivas ideológicas (ONCINA COVES, 2016, p. 13-16).

En el ámbito jurídico, la Constitución representa el texto central, que delimita la manera en que deberán desdoblarse las futuras producciones normativas más particulares, como es el caso de los códigos. Esa continuidad de fondo también implicará un seguimiento procedimental en términos de validez y eficacia (KELSEN, 1982, p. 201-224). Por su parte, en el ámbito literario, los relatos conservan ideas rectoras trabajadas en el período precedente. Las palabras se mantienen, pero las circunstancias contextuales instan a cambiar su sentido. El binomio "civilización y barbarie" será nuevamente utilizado por la crítica, a los fines de estudiar los tipos de cultura (VINTHER, 1989, p. 232-238). A los recorridos descriptivos y panorámicos de años anteriores, se le contrapone ahora la imputación específica que identifica con nombre y apellido: Martín Fierro, Juan Moreira, Santos Vega, Juan Cuello, Luciano Santos.

La crítica cultural se expresa en todos los saberes y hace mella en el imaginario social. Las narrativas legales y literarias funcionarán bajo los mismos mecanismos (LEGENDRE et al., 1982, p. 96). La nominalización establece modelos y categorías sociales y al mismo tiempo distribuye responsabilidades. Para ello, la movilidad de ambos discursos diferencia dos individuos: el ciudadano y el gaucho.

\section{Construcciones jurídicas y literarias de la sociedad}

Por momentos, el derecho y la literatura parecen acoplarse ideológicamente bajo una misma idea. Ilustradas/os escritoras/es se atribuyen la capacidad de ponerse en situación y hablan de igual a igual con los sujetos que proscriben. Así podremos ver como el gaucho llora su destino (CIURO CALDANI, 2008, p. 199), reniega de sus condiciones, transita su lugar, 
teme a la justicia sin conocerla y da muerte a sus contrarios con cuchillo en mano. La suerte de este individuo se presenta no como una fatalidad literaria, sino producto un efecto del despliegue jurídico (BURGOS, 2019, p. 16).

La Constitución ha habilitado las instituciones y los instrumentos para ello. El funcionamiento del Congreso hace escuchar el lenguaje del Estado. Las leyes comienzan a tener un rol protagónico en la construcción del modelo social que se propone. Para ello delimitan los parámetros de propia creación así como de su aplicación e interpretación. Desde lo legal, el poder se expresará sobre la propiedad, las regulaciones de los actos, la idea y existencia de las personas, las relaciones de familia, los delitos y sus castigos, las operaciones comerciales.

La fuerza de la razón, la aplicabilidad fáctica del progreso, el orden deseado, la sistematización social, el reduccionismo nominalista. Todo este formidable cúmulo ideológico encontrará su contención en los cuerpos legales que el derecho les ofrece en el Código Civil, el Código de Comercio o el Código Penal. Instrumentos que habilitarán a su vez, la instauración de normativas más específicas conforme la situación lo amerite.

Se produce el desgranamiento de los grandes relatos.

La atención se ha desplazado, por el contrario, de las vastas unidades que se describían como "épocas" o "siglos", hacia fenómenos de ruptura. Por debajo de las grandes continuidades del pensamiento, por debajo de las manifestaciones masivas y homogéneas de un espirito de una mentalidad colectiva, por debajo del terco devenir de una ciencia que se encarniza en existir y rematarse desde su comienzo, por debajo de la persistencia de un género, de una forma, de un disciplina, de una actividad teórica, se trata ahora de detectar la incidencia de las interrupciones. (FOUCAULT, 2008, p. 12)

Bajo la norma legal o el escrito literario, se constituye al individuo en ciudadano. Desde esas fronteras discursivas se ficcionaliza la subjetividad. Las formas de la cultura se leen. Luego se comentarán en las tertulias de salones, concurridos por un público selecto. Práctica que Schvartzman reconoce:

Un letrado escribe-transcribe lo que un gaucho ha dicho o cantado para que otro letrado, en la lectura, se represente una escena oral o la represente en alta voz para los letrados y no letrados que oyen. (SCHVARTZMAN, 2013, p. 45).

Al gaucho le han atribuido una voz que no es la suya. Un intérprete devenido en autor se ha tomado esa licencia y ha dado lugar a la gauchesca. Las obras de Juan Gualberto Godoy (El Constitucional) o Pedro Echagüe (Diálogos) se presentan como precursoras en el género al 
intentar imitar en sus escritos el habla de los payadores (FUCITO, 2010, p. 85-90). A ellos le seguirán otras producciones como Santos Vega o los mellizos de la Flor (1851) y Aniceto el Gallo (1853) de Hilario Ascasubi; Pablo ou la vie dans les Pampas (1868) de Eduarda Mansilla; Peregrinación de Luz del Día (1871) de Juan Bautista Alberdi; El porvenir (1872) de María Eugenia Echenique; Peregrinaciones de un alma triste (1875) de Juana Manuela Gorriti; Juan Moreira (1879) de Eduardo Gutiérrez.

No es un dato azaroso que este género adquiera notoriedad al momento en donde se proyecta la consecución de la identidad cultural. La integración implica una estereotipación e idealización del guacho como otredad. Esta construcción del individuo se observará en dos autores que si bien parten de concepciones políticas diferentes, comparten una misma pertenencia territorial, la ciudad.

El primero de ello será Estanislao del Campo en Fausto. Impresiones del gaucho Anastasio el Pollo en la representación de esta ópera (1866). El aspecto ficcional será fundamental en la propuesta de la obra. Desde el recurso literario de la parodia se propone la disputa en torno a la idea de representación de la realidad y la formación de la identidad. Su apoyatura en el aspecto literario intenta conducir a la despolitización y autonomía del discurso. La distancia del relato propone una lectura que marque las diferencias entre las narrativas ficcionales. Sin embargo, esa distancia permite extraer concepciones iusliterarias sobre la forma en que se entiende al gaucho y su participación en la sociedad.

E1 segundo autor será José Hernández con Martín Fierro (1872). Obra universal que permite dar cuenta de esa relación cercana de las narrativas jurídicas y literarias (GARCÍA, 1999, p. 179). Un análisis en términos estéticos implica no solo la delimitación del género sino el reconocimiento del gaucho como individuo. Esta función de la crítica literaria se instituye como un acto político-jurídico (FUCITO, 2010, p. 142-145). Reconocer la identidad del individuo implica reconocer la diferencia y habilitar los mecanismos de poder para su protección. Estos intercambios parecen acontecer en Martín Fierro.

Hernández reúne las dos narrativas y permite una lectura iusliteraria que aportará numerosas herramientas de análisis iusfilosóficas (CIURO CALDANI, 1984, p. 22-31). Fierro y Hernández, bárbaro y civilizado, critican expresamente la idea de justicia, su carácter arbitrario, sus fundamentos endebles y la gestión de sus operadores. Exponen las asimetrías entre los derechos y las obligaciones, los abusos de una autoridad, la indeterminación de los castigos, las normas que profundizan más las diferencias entre individuos según su origen (PALADIN, 2011, p. 10).

A diferencia de otras obras, Hernández propone un uso diferente de la tensión 
“civilización-barbarie". Ello lo lleva a que su personaje pertenezca a la cultura popular y al mismo tiempo se constituya como un autor esencial. No niega su origen, percibe su investidura letrada (PERNA, 2015, p. 199-202). La composición métrica del poema de cuenta de ello. A diferencia de otras obras, le otorga un nuevo lenguaje al gaucho. Martin Fierro continúa esa importancia denuncialista iniciada por Bartolomé Hidalgo en sus Cielitos (1816-1821) y luego por Antonio Lussich en Los tres gauchos orientales (1872). Propone nuevas formas de entender la identidad nacional, lo que implica la participación del ámbito jurídico y la modificación de las formas de entender la cultura.

\section{Bordes y penumbras del discurso iusliterario}

Hacéte amigo del juez, / no le des de que quejarse; / y cuando quiera enojarse / vos te debés encoger, / pues siempre es güeno tener / palenque ande ir a rascarse.-

(Martín Fierro)

\subsection{Del centro a los márgenes}

Procedentes de familias de marcada historia, formados en instituciones, eruditos lectores, miembros de grupos acaudalados, partícipes de actividades castrenses, profusos escritores que dan cuenta de un saber amplio, serán algunas de las características propias de los autores cuyas obras emergen con posterioridad a la sanción de la Constitución Nacional Argentina de 1853.

Muy cercanos al espíritu de amalgamiento y unidad que el texto legal propone, los escritores forjarán esas ideas en su literatura. El encuentro con otros espacios, los relatos de tierras lejanas empiezan a no ser tan fantásticos ni ajenos. Productos y acciones que se realizan más allá de los ruidos del centro, los ubican frente a un nuevo individuo que se diferencia de ellos y que deben identificar.

La discusión se debate entre una visión centralista (unitaria) y una perspectiva amplia de la repartición del poder (federal). La tensión se verá plasmada en términos iusliterarios y establecerá diferencias ideológicas entre sus autores. La construcción del otro divergido será un tema nodal en los textos de la época. Este punto en común implicará a su vez disidencias y dicotomías al momento de forjar su idea de nación. No resalta la confrontación hacia una colonización extranjera, la independencia no se discute. La mirada se dirigirá hacia la interioridad, allí donde habita la figura del gaucho, sobre la cual Sarmiento comentaba: 
Es preciso conocer al gaucho argentino y sus propensiones innata, sus hábitos inveterados. Si andando en la pampa, le vais proponiendo darle una estancia con ganado que lo haga rico propietario; si corre en busca de la médica de las alrededores para que salve a su madre, a su esposa querida que deja agonizando, y se atraviesa un avestruz por su paso, echará a correr detrás de él olivando la fortuna que le ofrecéis, la esposa o la madre moribunda. (...) Echa de memos su cuchillo, se vuelve a retomar aunque esté a una cuadra del lugar a donde iba; porque el cuchillo es para él lo que la respiración a la vida misma. (SARMIENTO, 1962, p. 212)

La construcción del gaucho, se verá atravesada por autores que parten de una misma pertenencia territorial pero de concepciones políticas diferentes. Esa clave de lectura nos parece nodal para el análisis de la gauchesca en términos iusliterarios (HERRERA, 1977, p. 97). Tal es el caso del Fausto de Estanislao del Campo y el Martín Fierro de José Hernández. La escritura de ambos parte de un mismo centro civilizado, pero que, sin embargo, en términos políticos se difumina hacia los bordes, lo que incide en su forma de entender al gaucho:

Poeta importante es Estanislao del Campo (Argentina, 1934-1880), cuya escritura -según Borges- ostenta de más vocabulario rural y carece medianamente de la mentalidad del paisano. Aunque el mismo Hernández haya acusado a Estanislao del Campo de no conocer al gaucho, éste resultaba difícil de conocer para la segunda mitad de 1800 en Buenos Aires, incluso: no se trataba de conocerlo, sino de no ignorarlo. (BOLAÑOS, 2016, p. 115)

Estas diferencias se plasman en sus obras literarias y la crítica que se hará sobre ellas y la literatura gauchesca en general (LUDMER, 2019, p. 63-74). En este sentido expone Darnet de Ferreyra:

Del Campo no se identifica con gauchos como lo hiciera Ascasubi y habría de hacerlo luego Hernández, antes bien permanece siempre en el plano distinto de al de aquellos, a los que suele mirar con cierto dejo de irónica socarronería. Hasta el mismo lenguaje gauchesco del poema no es en realidad hábil remedo de un poeta culto e ingenioso. (DARNET DE FERREYRA, 1950, p. 168)

Las obras emergen con posterioridad o bien se adelantan a otras producciones en las que también se grafica una determinada imagen del gaucho. Al igual que Paulino Lucero (1843), Aniceto el gallo (1853) y Santos Vega (1872) de Hilario Ascasubi, Juan Moreira (1879) de Eduardo Gutiérrez o el Fausto (1866) de Estanislao del Campo, el Martín Fierro propondrá sus propias perspectivas. Para poder identificarlas, será necesario diseccionar sus textos y 
pensar las formas iusliterarias en que componen ese nuevo individuo y sus vinculo con la organización política y social argentina del momento (GUTIÉRREZ, 2011, p. 313).

\subsection{De los márgenes al centro}

El personaje principal del Martín Fierro (1872) habla en primera persona, en nombre de un pueblo, con su propia lengua (PERNA, 2015, p. 203-205). Este recurso intenta convertirlo en palabra autorizada para justificar lo que canta: "Soy gaucho, y entiéndanló / como mi lengua lo esplica" (HERNÁNDEZ, 2010, p. 32).

El lenguaje nacional lo distancia de otras formas importadas y al mismo tiempo marca una ruptura en el modo en que se debe entender y montar la nación:

La lengua del Martín Fierro entronca - es indudable- con la lengua literaria gaucha: una lengua apoyada en la realidad del gaucho, peor que es, al mismo tiempo, producto de afinamiento literario. (HERNÁNDEZ, 2010, p. 17)

El sufrimiento patriótico que corre por sus versos, sumado al heroísmo mesiánico y la experiencia de haber estado afuera de los límites legales, le permiten desde la experiencia, dar cuenta de una forma de existencia que "llegó al alma misa del pueblo, que la reconoció como suya, tan suya, que sus ediciones se vendían en pulperías de campaña junto con los fósforos, la cerveza y las sardinas" (DARNET DE FERREYRA, 1950, p. 171).

Formas y fondo que parecen omitir el lenguaje de un individuo que deja su espacio urbano, que modela su lenguaje. Saca su mirada hacia el extranjero y la dirige hacia el interior (CIURO CALDANI, 1986, p. 103). Aquí el espacio de la literatura gauchesca, como denuncia de las injusticias que la ciudad ha instaurado en el campo. En este sentido expone Sarlo:

La ciudad no es el contenido de una obra, sino su posibilidad conceptual. Todos los desvíos rurales de la literatura rioplatense de este siglo son producidos por la ciudad y desde ella: se sale de la ciudad a escribir sobre el campo. La literatura visita el campo, pero vive en la ciudad. (SARLO, 2015, p. 8)

Profusa será la nómina de trabajos y estudios en torno a la obra, la cual propone interesantes estudios en clave "derecho-literatura". En términos iusfilosóficos, el Martín fierro permite acceder a la forma y organización de las instituciones legales. En este sentido la literatura podría: 
Haber colaborado con el imaginario destituyente del derecho, idea a la que el mismo Hernández (y mucho más Gutiérrez) contribuyeron. La difusión de esas obras (y la trascendencia teatral popular de la obra de Gutiérrez) tuvo su base cultural y colaboró con ella. Un siglo y medios después, nos preguntamos por qué tantos incumplen tantas normas, y hace lo que les viene en gana, sin que nadie se ocupe de ello. Habría que contestar porque se han unido demasiadas variables históricas en contra de la ley. (CALVO GONZÁLEZ, 2016a, p. 71)

Lentamente, la literatura es fagocitada por las referencias jurídicas. Se trata de un espacio que todo lo ocupa. Decir que el gaucho llora su suerte, que se discuten sus condiciones de vida diarias, el temor que lo invade entre payada y payada en tanto aparezca la autoridad, la forma en que entiende su familia, su enemigo, su grupo y a sí mismo, implica pensar como el derecho interviene en sus formas de vida.

\begin{abstract}
¿Es posible entender al Código Civil de la propiedad privada y la libertad de contratación fuertes desarticulándolo de la estrategia de desarrollo científico y tecnológico, de la aplicación rigurosa de la ley de vagos y mal entretenidos que permitía la muerte del indio o del gaucho, de la escuela que terminaría siendo laica, común, gratuita y obligatoria y de la política migratoria destinada a traer europeos con sentido del trabajo y la empresa? ¿Se puede comprender el Código Civil que comenzó a regir en 1871 sin atender a que en 1872 el gaucho lloró su desgracia en la primera parte de Martín Fierro? (CIURO CALDANI, 2008, p. 198-199)
\end{abstract}

A lo largo de su obra, Hernández experimenta el fenómeno de la identidad y las subjetividades en los personajes que emergen, construidos desde las libertades que permite la ficción. Tal será el caso de Fierro, a quien desde los primeros versos le otorga voz propia para cantar su verdad:

Aquí me pongo a cantar / al compás de la vigüela, / que el hombre que lo desvela / una pena extraordinaria, / como la ave solitaria / con el cantar se consuela. / Pido a los dantos del cielo / que ayuden mi pensamiento: / les pido en este momento / que voy a cantar mi historia / me refresquen la memoria / y aclaren mi entendimiento. (HERNÁNDEZ, 2010, p. 29)

Cárcova expone que "ficción y realidad; identidad y subjetividad, juegan esquivos papeles en la construcción racional del derecho" (CÁRCOVA, 2000, p. 1). En Martín Fierro la figura del guacho es abordada de una forma diferente de otros relatos antecedentes. No responde a las mismas que habían sido sostenidas por otras construcciones y ello hace tambalear los cimientos de la verdad en el relato. Alguna vez hubo un gaucho abominable y execrable, un antihéroe necesario por la tragedia y capaz de movilizar la acción. La identidad del personaje 
permite una relectura diferente. Los cimientos literarios movilizan su canon y dan cuenta de la fuerza que la ficcionalización tiene en la formación de subjetividades.

Como expresan José Gutiérrez y Víctor Silva:

La identidad y la alteridad son construcciones intelectuales que se confirman en su carácter relacional; se afirman en la singularidad y la diferencia. La singularidad reclama necesariamente un exterior de confrontación que mida la identidad en cuanto construcción que inaugura el campo de lo humanamente posible. La diferencia, presencia fantasmagórica de la singularidad, necesita poseer un "locus" que también habilite y permita su existencia. (GUTIÉRREZ - SILVA, 2001, p. 1)

Nacida desde la escritura, la identidad del gaucho se construye y adquiere otros aspectos. Hernández le dará al payador una moldura no solo estética sino también ética. Identidad que será discutida por la literatura posterior, como es el caso del mismo Borges, quien hará numerosas intervenciones (GARCÍA MORALES, 2000, p. 30). Los cuentos El fin y Biografía de Tadeo Isidoro Cruz (1829-1874), o el breve texto en el que describe el crimen del moreno en la pulpería titulado de la misma manera que el de Hernández. También lo harán Biografía de Tadeo Cruz o el cierre paradójico, no solo literario sino también metafísico, que marca El fin:

Era un paisano decente, respetado de todos y respetuoso, ahora es un vagabundo y un desertor. Para la sociedad, es un delincuente, y ese juicio general hace que lo sea, porque todos propendemos a parecernos a lo que piensan de nosotros. (BORGES; GUERRERO, 1999, p. 19)

Desde sus narrativas, la literatura y el derecho problematizan sus identidades así como la identidad de sus sujetos. En este sentido la categoría de análisis que proponemos se aparta de las visiones esencialistas. Karam de Chueiri expresa:

(Nuestra) identidad es intermediada por recursos institucionales de reconocimiento (...). El estado y el derecho tienen la autoridad para definir la identidad de alguien (la nuestra) y también por qué el estatus de su (nuestra) identidad, una vez establecida por las autoridades, nunca permite una identidad separada por guiones. (KARAM DE CHUEIRI, 2014, p. 44-45)

El núcleo pulveriza el pensamiento, obliga a indagar en creaciones potenciales y humanas. No hay nada universal, solo nombres, recortes que hacemos sin la necesidad de responder a entidades trascendentales. La idea del nombre como creador y capaz de modelizar 
la realidad desde las palabras no solo fija una concepción en términos de libertad sino también una forma de comprender la realidad que percibimos, entre el hecho y las letras encadenadas.

En la narración, al igual que el contexto espacio-temporal, los sujetos intervinientes son pasibles de construcción en todo momento, de cada acontecimiento anteriormente relatado. Hay un sinfín de posiciones y construcciones argumentativas que de un modo $u$ otro inciden en el modo en que las conocemos, concebimos y formamos al sujeto.

En el Martín Fierro, el payador necesita de pruebas a los fines de darle la veracidad a su canto. El narrador se siente exigido a dar muestras de los instrumentos desde los que se ha constituido la fama de su condición.

\footnotetext{
El nada gana en la paz / y es el primero en la guerra; / no le perdonan si yerra, / que no saben perdonar, / porque el gaucho en esta tierra / solo sirve pa votar. / Para él son los calabozos, / para él las duras prisiones; / en su boca no hay razones / aunque la razon le sobre; / que son campanas de palo / las razones de los pobres. (HERNÁNDEZ, 2010, p. 76)
}

Muchos ejemplos son capaces de ilustrar esta formación del relato, que creemos mirar desde afuera, de modo acrítico y autoevidente, pero sin embargo no está libre de los procesos de formación subjetiva.

Una constante pugna entre el sujeto que se construye y es construido. Frente a esa tensión por establecer la representación correcta, se hará todo lo posible por evitar todo intento por cambiar el modelo, a través del rechazo de aquellas opiniones que afecten nuestra forma de mostrarnos al mundo, nuestra dignidad, nuestra estética social, en resumen, nuestro honor. Esta suerte correrá el Martín Fierro, quien constantemente deberá dar cuenta de quien dice ser. El personaje se construye desde las palabras de los sujetos y en este caso la justicia será la encargada de establecer la verdad del mismo:

Con la guitarra en la mano / ni las moscas se me arriman; / naides me pone el pié encima, / y cuando el pecho se entona, / hago gemir á la prima / y llorar á la bordona. / Yo soy toro en mi rodeo / y torazo en rodeo ajeno; / siempre me tuve por güeno / y si me quieren probar / salgan otros á cantar / y veremos quién es menos. (HERNÁNDEZ, 2010, p. 31)

Los individuos son pasibles de construcción constantemente, los cuales deben erigir o en todo caso dar los planos para que se lleve a cabo de modo correcto, en pos de proteger su honor. Este concepto no solamente implica fama, respeto, dignidad o estima sino algo mucho más importante: la pertenencia a un grupo social, el sentirse "parte de", evitar el ostracismo social. Perder el honor es perder identidad, el nombre, la forma en que nos conocen y nos tratan. 


\section{Subjetividad, justica y poder}

En la obra de José Hernández, la idea de justicia aparece como gran movilizador de su producción. En su universo textual, este tópico tendrá fuerte vinculación con otras temáticas, a saber, el coraje, la cobardía, la soledad, la delación y la traición.

El enfrentamiento entre el honor y la infamia al cual se ve arrojado el gaucho, será lo que va a permitir que la acción avance. El motor que impulsa la acción, si bien puede hacerse tangencial desde la partida de policías, implica una perspectiva mucho más amplia. La movilidad transita de manera espectral, una idea de justicia persigue al gaucho, hasta asfixiarlo sobre todo en términos ideológicos:

Que ya no hablaban tampoco, / me lo dijo muy de cierto, / de cuando con la partida / llegué á tener el encuentro. / Esa vez me defendí / como estaba en mi derecho, / porque fueron á prenderme / de noche y en campo abierto. / Se me acercaron con armas, / y sin darme voz de preso, / me amenazaron á gritos, / de un modo que daba miedo, / que iban arreglar mis cuentas, / tratándome de matrero, / y no era el gefe el que hablaba / sinó un cualquiera de entre ellos. (HERNÁNDEZ, 2010, p. 168)

Aquí la temática de la justica es central. El gaucho no quiere se lo nombre sin previo control de lo que se dice ni quedar como "algo que no es" para con la sociedad. Para ello hará uso de cualquier medio para cuidar de que no cambien el estado de las cosas, de su entorno sin importar las implicancias, moviéndose en las fronteras del relato oficial y unívoco.

La ley se hace para todos, / mas solo al pobre le rige. / La ley es tela de araña, / en mi inorancia lo esplico: / no la tema el hombre rico, / nunca la tema el que mande, / pues la ruempe el vicho grande / y solo enrieda á los chicos. / Es la ley como la lluvia: / nunca puede ser pareja; / el que la aguanta se queja, / pero el asunto es sencillo, / la ley es como el cuchillo: / no ofende á quien lo maneja. (HERNÁNDEZ, 2010, p. 259-260)

Esa vida errante, descentrada, ajena y foránea que lo llevan a ser gaucho matrero supone la necesidad de introducir nuevas normas (para-derecho, derecho no oficial-estatal, alternativo).

Que el Juez que me perseguía / hacia tiempo que era muerto: / por culpa suya he pasado / diez años de sufrimiento, / y no son pocos diez años / para quien ya llega á viejo. / Y los he pasado ansi, / si en mi cuenta no me yerro: / tres 
años en la frontera, / dos como gaucho matrero, / y cinco allá entre los Indios / hacen los diez que yo cuento. (HERNÁNDEZ, 2010, p. 166-167)

No es de sorprender que la fuerza física sea la ley general que pretenda imponerse sobre la ley estatal, la autoridad (ARGAÑARAZ ALCORTA - PAGANO, 2014, p. 35). Desde la mirada de Fierro, la institucionalización de la violencia, de manera necesaria, prevalece sobre la norma positiva y sus formas de aplicación.

Se hace imperioso el uso de la fuerza, la cual estará íntimamente ligada a la idea de valentía. El fuerte, el que mejor maneje el cuchillo, se hará valer sobre los demás y dará cuentas de quién es, sin dejar que ningún relato externo los intente cambiar. El texto así encontrará una vinculación primordial entre la fuerza y la inocencia. Omitida la solución desde las palabras, la violencia debe hacerlo entender:

Me hirbió la sangre en las venas / y me le afirmé al moreno, / dandole de punta y hacha / pa dejar un diablo menos. / Por fin en una topada / en el cuchillo lo alcé, / y como un saco de güesos / contra un cerco lo largué. (HERNÁNDEZ, 2010, p. 71)

La ignorancia de Fierro ante una ley que se pretende conocida por todos, no hace más que resaltar uno de los numerosos mitos y opacidades del derecho (FITZPATRICK, 1998, p. 78-89). Asustado frente a una culpa que desconoce, un proceso que desconoce, no sabe de qué se trata ni tampoco cómo resolverlo:

Me dijo, á mas, ese amigo / que andubiera sin recelo, / que todo estaba tranquilo, / que no perseguia el Gobierno, / que ya naides se acordaba / de la muerte del moreno, / aunque si yo lo maté / mucha culpa tuvo el negro. (...) / Él, de engreido me buscó, / yo ninguna culpa tengo; / el mesmo vino á peliarme, / y tal vez me hubiera muerto / si le tengo mas confianza / o soy un poco mas lerdo; / fué suya toda la culpa, porqué ocasionó el suceso. (HERNÁNDEZ, 2010, p. 167-168)

Solo desea su retorno y allí, cuando para hacerlo debe cambiar, debe volver. La ley que le niega la ley, lo asfixia y atosiga. La culpa inexplicable y la inocencia reclamada. El rencor al discurso que categoriza y ordena (CATALFAMO, 1999, p. 56).

La vertiginosidad de la obra parece llevarnos constantemente a través de una persecución que el mismo Cruz nos advierte y nos interroga como lectores en torno a un hombre inocente al quien han obligado a dejar todo, su familia, sus terrenos, su afecto, su entorno, su espacio, su domesticidad, todo ello que permite aflorar su desconsuelo. Fierro no puede defenderse en términos legales, solo puede hacerlo desde el cuerpo. 
El derecho establece su verdad jurídica. Las resoluciones no se debaten en un plano de igualdad entre los sujetos implicados. Un tercero implicado controla también indica lo que corresponde. La fuerza monopolizada en un órgano poseedor de la verdad. Ahora se instituyen los medios de prueba, se les otorga la calidad de válidos o inválidos a los fines de establecer la solución correcta del caso. Es una sola y unívoca forma de solucionar. La norma estatal se impone en todos los espacios y justifica el uso de la fuerza en sus más variados aspectos, sea con la cárcel, el ostracismo o la muerte.

La arbitrariedad institucional en el ejercicio de justicia atraviesa gran parte de Martín Fierro. Por ello la valentía expresada en términos de fuerza es el instrumento por excelencia para hacer valer la defensa. Un sujeto que irrumpe se impone desde su nombre. No es necesaria la institucionalización, no se quiere la participación del Estado sino que la solución solo se consigue con la intervención de los implicados. La verdad establecida de modo inmediato, la verdad del más fuerte, como única regla exigida para dirimir las disputas y funcionar como veredicto final.

Los testimonios silenciados, la fuerza de la palabra compartida, las pruebas comunes, son los instrumentos para arribar a lo que debe ser. Nadie osa cuestionar las formas de justicia paralelas. Está institucionalizada una actitud, dispuesta a no ser compartida con la ley. No es necesaria la presencia de un tercero que se arrogue la capacidad de dirimir la disputa, más si nunca estuvo presente en el hecho. Un espacio que no tiene intenciones ni ánimos de querer formar parte y emparentar con la ley oficial (HERNÁNDEZ, 2010, p. 175).

Ninguno quiere la participación de otro, el miedo latente de perder su identidad bajo otro discurso, de no sentirse igual al otro. Sujetos que han sido "sujetados" a una forma de verse y participar en su entorno. La ideología así unida indefectiblemente a los límites de lo cognoscible. Los significados ocultos y el poder forman una estructura cerrada, que se autoabastece y se transforma sobre sí misma:

El "núcleo" preideológico de la ideología consiste, entonces, en la aparición espectral que llena el hueco de lo real. Esto es lo que no tienen en cuenta todos los intentos de trazar una línea clara de separación entre la "verdadera" realidad y la ilusión (o de fundamentar la ilusión de la realidad): si (lo que experimentamos como) la "realidad" debe emerger, algo debe ser excluido de ella; es decir, la "realidad", como la verdad, por definición, nunca está "completa". (ZIZEK, 2003, p. 32)

Desde una maquinaria sutil, la ideología convierte al sujeto en parte de su estructura (con límites, reglas, obligaciones, derechos). Lo constituye como parte propia de "su reflexión 
práctica". El individuo percibe la idea de "sujeto" como natural a la sociedad, necesario y único. Sin embargo la noción conceptual es prescindible e intercambiable. Las relaciones imaginarias forjadoras de subjetividades comprenden imágenes, prácticas, conceptos, construcciones y estructuras adoptadas a nivel inconsciente. Dentro de este campo, la ideología funciona como el marco de representación sobre el que se construyen los sujetos en sus condiciones reales de existencia. Crea el mapa imaginario que comprende la totalidad dentro de la cual desarrolla sus mecanismos. Pone nombres, da derechos, todo ello está previsto: "Y yo empujao por las mias / quiero salir de este infierno; / ya no soy pichon muy tierno / y sé manejar la lanza / y hasta los indios no alcanza / la facultá de Gobierno" (HERNÁNDEZ, 2010, p. 104).

Lo ideológico constituye la subjetividad humana. La ideología configura los individuos como sujetos, los reconoce como tales, pero al mismo modo los excluye porque dicha subjetividad es construida desde dimensiones imaginarias que lo hacen desconocer y eluden sus reales condiciones de vida. En ello radica la nueva dimensión atribuida a este fenómeno, en que no se trata solamente de una visión deformada de la realidad ni de un instrumento necesario en las relaciones de producción, sino también de la producción, construcción y conservación de subjetividades. El individuo accede a una estructura que le permite participar en su constitución como sujeto, pero dicha participación lo sujeta y lo estereotipa; es decir, la función de la ideología es otorgarle participación al mismo tiempo que se la niega. La estructura ideológica establece una determinada producción de sujetos humanos. Establece los límites de identificación, formación y construcción social de la subjetividad.

El derecho en el Martín Fierro solo posee un aspecto formal. Las fuerzas del Estado son testigo pasivo de que se cumple con la aparente regularidad del buen desarrollo y el respeto de la normativa. Las únicas pruebas son las que quedan entre ellos, lo que entre ellos se dijeron y lo que entre ellos ha sido aceptado. Es un espacio que no tiene intenciones ni ánimos de querer formar parte y emparentar con la ley oficial, cuya expresión de fuerza se dará en la policía. El nombre del guapo puede lucirse, porque nadie va a decir nada. La fuerza lo instituye como tal y el nombre lo mantiene altivo hasta su próxima disputa por el honor, disputa que no será otra cosa que la pugna por manejar la palabra. Hablar del otro, decir algo de él, informar, denunciarlo, exponerlo y desnudarlo. Construirlo desde el relato, siempre de manera intencionada, siempre orientado hacia algo. En este sentido expone Ruiz:

Los hombres toman conciencia de ser hombres, a través de toda una red de mediaciones que los condicionan, y determinan las relaciones que pueden establecer unos con otros, constituyéndolos como sujetos. (RUIZ, 2001, p. 129) 
La formación de la persona jurídica capaz de adquirir derechos y contraer obligaciones es una construcción que tiene implícita o explícitamente en cuenta una determinada serie de discursos antropológicos, sociológicos y culturales, entre otros. La búsqueda de la verdad, el discurso hegemónico, la delación como forma de verdad, la infamia y la cobardía en la que nos vemos inscriptos a causa de ese acto acusatorio, la constitución del sujeto desde la palabra y la parte importante que cumple el nombre como principal imagen de presentación y su obligación por proteger: todas estas cuestiones son categorías pasibles de construcción desde una miríada de discursos, entre ellos el discurso jurídico. El derecho no aparece después del sujeto, sino que viene a constituirlo, a ponerlo en situación, a contextualizarlo en un determinado orden; en definitiva, sujeta al sujeto a un entramado particular. La ley lo nombra, lo resignifica y le da su lugar correspondiente en el entramado social..."lex, ergo sum": "Aquel que tiene buen nombre / muchos dijustos ahorra; / y entre tanta mazamorra / no olviden esta alvertencia: / aprendí por esperencia / que el mal nombre no se borra" (HERNÁNDEZ, 2010, p. 235-236).

\section{Conclusión}

En Destino del sujeto en las paradojas de la cultura jurídica, Maresca intenta abordar la temática del sujeto desde nuevas perspectivas. Propone elaborar "un discurso sobre el sujeto que fuera dependiente de un pensamiento no secularizado, idealista y humanista" (MARESCA, 1994, p. 132).

La perspectiva de un sujeto libre y autónomo pasa a ser entendido como individuo sujetado e históricamente constituido. No se trata de sujetos de derecho, sino del derecho que sujeta a los individuos a un determinado espacio y los constituye de una determinada manera. No hay una construcción originaria, porque no hay sujeto por fuera de la interpelación. Desde su estructura ficcional, el discurso jurídico interpela y constituye.

El discurso jurídico forma, desplaza, silencia, censura y excluye desde su red racional en torno a la idea de orden que pretende instaurar. El abordaje interdisciplinario y narrativista propuesto intenta desmitificar la enraizada noción de un sujeto libre y autónomo, con todo lo que ello implica. Su propuesta apunta a desarticular estos espacios ficcionales como cualidades esenciales de lo humano, para dar cuentas de que las formas sociales lo constituyen y sostienen como tal: 
Los hombres no son "sujetos de derecho" sino que son "sujetos barrados". El derecho los interpela y los constituye. Interpelación y constitución remiten a la dimensión ideológica del discurso jurídico. La interpretación no es única, el derecho interpela de modos diversos y múltiples, no hay todo un juego interpelatorio heterogéneo. (RUIZ, 2001, p. 93)

Hernández visibiliza cómo la ficción permite edificar diferentes tipos de subjetividades. Esta perspectiva expone la imposibilidad de establecer identidades absolutas y perspectivas esencialistas en torno a la concepción de la idea de sujeto. En estas instancias, la ideología tiene un rol activo en torno a los límites de lo cognoscible. En Martín Fierro, lo ideológico funciona como el marco de representación sobre el que se construyen los personajes de sus textos. Se establece los límites de identificación, formación y construcción social de la subjetividad.

Este planteamiento en torno al espacio del sujeto en el que nos inserta Martín Fierro también es compartido por el espacio jurídico. El discurso del derecho adquiere así una relevancia por sobre la realidad, lo que incluye la figura del individuo, en su consideración general.

\section{Referencias}

ARGAÑARAZ ALCORTA, Rodolfo; PAGANO, José León. El Martín Fierro en la literatura y en el derecho penal. Buenos Aires: Cathedra Jurídica, 2014.

BORGES, Jorge Luis; GUERRERO, Margarita. El Martín Fierro. Buenos Aires: Alianza, 1999.

BURGOS, Osvaldo. Justicia y derecho en las idas y vueltas de Martín Fierro: la propuesta de una lectura única. In: Derecho y Cambio Social, Lima, $n^{\circ}$ 58, 2019, p. 11 a 37. Disponible en: https://lnx.derechoycambiosocial.com/ojs-3.1.1-

4/index.php/derechoycambiosocial/article/view/256. Acceso en: 02 may. 2021.

CALVO GONZÁLEZ, José. Borges en el espejo de los juristas. Derecho y literatura borgeana. Pamplona: Aranzadi, 2016a.

CALVO GONZÁLEZ, José. Justicia constitucional y literatura. Lima: Centro de Estudios Constitucionales del Tribunal Constitucional, 2016b.

CALVO GONZÁlEZ, José. La destreza de Judith. Estudios de cultura literaria del derecho. Granada: Comares, 2018.

CALVO GONZÁLEZ, José. Proceso y narración. Teoría y práctica del narrativismo jurídico. Lima: Palestra, 2019. 
CÁRCOVA, Carlos María. Cine, ficciones y derecho. In: Revista asociación de abogados de Buenos Aires", año 2000, p. 1. Disponible en http://www.saij.gob.ar/doctrinaprint/dacf010069-carcova-cine_ficciones_derecho.htm. Acceso en: 05 abr. 2021.

CÁRCOVA, Carlos María. La opacidad del derecho. Madrid: Trotta, 2007.

CATAlfamo, Pedro Juan. Martín Fierro ante el Derecho Penal. Buenos Aires: Printers, 1999.

CIURO CALDANI, Miguel Ángel. Comprensión jusfilosófica del "Martín Fierro": nociones básicas de filosofía jurídica literaria, aportes sobre justicia y belleza. Rosario: Fundación para las Investigaciones Jurídicas, 1984.

CIURO CALDANI, Miguel Ángel. Entrevista al Dr. Miguel Ángel Ciuro Caldani. In: Lecciones y Ensayos, Buenos Aires, $\mathrm{n}^{\mathrm{o}}$ 85, 2008, p. 191 a 205. Disponible en: http://www.derecho.uba.ar/publicaciones/lye/pub_lye_numeros_85.php. Acceso en: 26 abr. 2021.

CIURO CALDANI, Miguel Ángel. Filosofía, Literatura y Derecho. Rosario: Fundación para las Investigaciones Jurídicas, 1986.

DARNET DE FERREYRA, Ana Julia. Historia de la Literatura Americana y Argentina. Buenos Aires: Estrada, 1950.

FITZPATRICK, Peter. La mitología del derecho moderno. Buenos Aires: Siglo XXI, 1998.

FOUCAULT, Michel. La arqueología del saber. Buenos Aires: Siglo XXI, 2008.

FUCITO, Felipe. La crisis del derecho en la argentina y sus antecedentes literarios. Un enfoque sociológico. Buenos Aires: Eudeba, 2010.

GARCÍA MORALES, Alfonso. Jorge Luis Borges, autor del Martín Fierro. In: Variaciones Borges, Pittsburgh, $\mathrm{n}^{\mathrm{o}}$ 10, 2000, p. 29-64. Disponible en: https://www.borges.pitt.edu/product/31. Acceso en: 09 may. 2021.

GARCÍA, Carlos. Borges y el "endiosamiento" de Hernández. In: Variaciones Borges, Pittsburgh, $\mathrm{n}^{\circ}$ 8, 1999, p. 178-186. Disponible en: https://www.borges.pitt.edu/product/29. Acceso en: 17 abr. 2021.

GUTIÉRREZ, Eduardo. Juan Moreira. Buenos Aires: Clarín, 2011.

HERNÁNDEZ, José. Martín Fierro. Buenos Aires: Losada, 2010.

HERRERA, Marcos. Martín Fierro y la ley penal. In: Universidad, Santa Fe, no 86, 1977, p. 95-113. Disponible en: https://bibliotecavirtual.unl.edu.ar:8443/xmlui/handle/11185/4929. Acceso en: 23 mar. 2021. 
KARAM DE CHUEIRI, Vera. Kafka, identidad(es) y autoridad(es): ejercicios de Filosofía, Derecho y Literatura. In: CÁRCOVA, Carlos María (coord.). Los derechos fundamentales en la constitución: interpretación y lenguaje. Buenos Aires: Abeledo Perrot, 2014.

KELSEN, Hans. Teoría Pura del Derecho. Ciudad de México: Universidad Nacional de México, 1982.

LEGENDRE, Pierre; ENTELMAN, Ricardo; KOZICKI, Enrique; ABRAHAM, Tomas; MARÍ, Enrique; LE ROY, Etienne; VEZZETTI, Hugo. El discurso jurídico. Perspectiva psicoanalítica y otros abordajes epistemológicos. Buenos Aires: Hachette, 1982.

LUDMER, Josefina. El género gauchesco. Un tratado sobre la patria. Buenos Aires: Eterna Cadencia, 2019.

MARESCA, Mariano. Destino del sujeto en las paradojas de la cultura jurídica. In: Crítica jurídica, Ciudad de México, $\mathrm{n}^{\mathrm{o}}$ 15, 1994, 131 a 145. Disponible en: https://revistascolaboracion.juridicas.unam.mx/index.php/critica-juridica/article/view/3139. Acceso en: 18 abr. 2021.

MARÍ, Enrique. Racionalidad e imaginario social en el discurso del orden. In: Doxa, Alicante, no 3, 1986, p. 93 a 111. Disponible en: https://doxa.ua.es/article/view/1986-n3-racionalidad-eimaginario-social-en-el-discurso-del-orden. Acceso en: 06 may. 2021.

ONCINA COVES, Faustino. El silencio en la Historia de las Ideas: Introducción y tentativas taxonómicas. In: Quaderns de filosofía, Valencia, vol. 3, nº 1, 2016, p. 11-24. Disponible en: https://roderic.uv.es/handle/10550/53235. Acceso en: 12 abr. 2021.

PALADIN, Gabriela. Hombres de ley, hombres sin ley: cruces entre derecho y literatura. Buenos Aires: Biblos, 2011.

PERNA, Carlos Gabriel. Fuentes históricas para el estudio de la lengua en la pampa en el siglo XIX (I): el Martín Fierro y la tradición de la gauchesca. In: Revista del instituto de lingüística, Buenos Aires, $\mathrm{n}^{\mathrm{0}}$ 27, 2015, p. 197-222. Disponible en: http://revistascientificas.filo.uba.ar/index.php/sys/article/view/3193. Acceso en: 18 may. 2021.

RUIZ, Alicia. Idas y vueltas por una teoría crítica del derecho. Buenos Aires: Editores del Puerto, 2001.

SARLO, Beatriz. Borges, un escritor en las orillas. Buenos Aires: Siglo XXI, 2015

SARMIENTO, Domingo Faustino. Facundo o civilización y barbarie en las pampas argentinas. Buenos Aires: Sopena, 1962.

SCHVARTZMAN, Julio. Letras gauchas. Buenos Aires: Eterna Cadencia, 2013.

VINTHER, Thora. Barbarie y civilización en "Martín Fierro". In: Biblioteca Virtual "Miguel de Cervantes", 2011. Disponible en http://www.cervantesvirtual.com/obra-visor/barbarie-ycivilizacion-en-martin-fierro/html/e2d74b0a-a0f8-11e1-b1fb-00163ebf5e63_4.html. Acceso en: 10 mayo. 2021. 
ZIZEK, Slavoj (comp.). Ideología. Un mapa de la cuestión. Buenos Aires: Fondo de Cultura Económica, 2003.

Data de recebimento: 08.04.2021

Data de aprovação: 28.07.2021 